\title{
Cyclophosphamide Suppression
}

\section{of Established Cell-Mediated Immunity}

\author{
QUANTITATIVE VS. QUALITATIVE CHANGES \\ IN LYMPHOCYTE POPULATIONS
}

\author{
James E. Balow, Douglas L. Hurley, and Anthony S. Fauci \\ From the Laboratory of Clinical Investigation, National Institute of Allergy \\ and Infectious Diseases, National Institutes of Health, \\ Bethesda, Maryland 20014
}

\begin{abstract}
A в S T R A C T The characteristics of cyclophosphamideinduced suppression of established cell-mediated immunity were studied in guinea pigs previously sensitized to tuberculin. Cyclophosphamide treatment for 5 days produced a dose-dependent peripheral lymphocytopenia and a disproportionately greater neutropenia which was particularly striking at high doses of $20 \mathrm{mg} / \mathrm{kg}$ per day (approximately $200 \mathrm{mg} / \mathrm{m}^{2}$ per day). Lymphocytes remaining in the circulation of cyclophosphamidetreated animals showed a dose-dependent reduction of both in vitro proliferative and macrophage migration inhibitory factor responses to tuberculin compared to lymphocyte responses of controls. Proliferative responses to phytohemagglutinin and concanavalin $\mathrm{A}$ were not significantly suppressed. Additional studies showed that cyclophosphamide suppressed the proliferative and $\mathrm{mi}$ gration inhibitory factor responses to tuberculin of lymph node and splenic as well as circulating lymphocyte populations. These studies showed that relatively short-term cyclophosphamide administration produced immunosuppression by quantitative as well as qualitative changes in lymphocyte populations. Significant suppression of lymphocyte function, however, was achieved only with doses of cyclophosphamide which also produced a severe neutropenia.
\end{abstract}

\section{INTRODUCTION}

Striking alterations of host defense mechanisms during the course of cyclophosphamide $(\mathrm{CY})^{1}$ therapy are well-

\footnotetext{
Received for publication 2 December 1974 and in revised form 26 February 1975

${ }^{1}$ Abbreviations used in this paper: CFA, complete Freund's adjuvant; Con A, concanavalin A; CY, cyclophos-
}

recognized features of its use in clinical medicine. Although several tissues are potentially susceptible to the toxic effects of CY, the particular sensitivity of the lymphoid system in man and experimental animals has led to investigation of the use of CY in autoimmune and chronic inflammatory diseases. Dramatic results of short-term CY therapy have been obtained in experimental models of immunologically mediated diseases and in certain types of human diseases $(1,2)$. However, clinical conditions requiring high dose and/or longterm therapy are fraught with considerable hazard due to concomitant suppression of host defense mechanisms $(1,3)$. These complications occur, at least in part, because of our currently incomplete knowledge of the mechanism of action of CY beyond its general classification as an alkylating agent. For example, it is unclear whether $\mathrm{CY}$-induced immunosuppression results from specific defects in lymphoid cell function or simply from induction of lethal effects leading to depletion of lymphoid cells. The ability of $\mathrm{CY}$ to affect nondividing, as well as rapidly dividing lymphocytes renders it a useful agent to alter preexisting immunocompetence (4).

The present studies were undertaken to further characterize the nature of effective suppression by CY of established cell-mediated immune reactions. The guinea pig was used for study because in vitro correlates of cell-mediated immunity are technically and theoretically

phamide; LNL, lymph node lymphocytes; MEM-S, Eagle's minimal essential medium, Spinner modification; MIF, migration inhibitory factor; $\mathrm{PBL}$, peripheral blood lymphocytes; PEC, peritoneal exudate cells; PHA, phytohemagglutinin; PPD, purified protein derivative of tuberculin.

The Journal of Clinical Investigation Volume 56 July 1975.65-70 


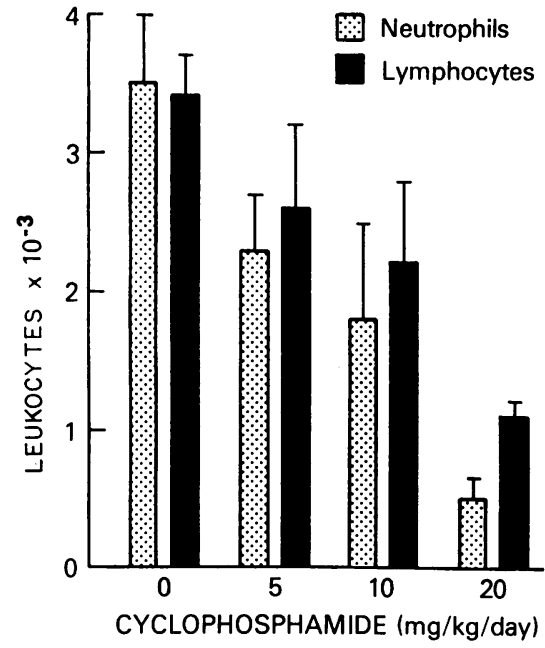

FIGURE 1 Effect of CY on peripheral blood leukocytes. Leukocyte counts and differentials were performed after a 5-day course of CY in the doses indicated. Values represent the mean ( \pm SEM) leukocyte count of six animals per group.

well defined (5), and animal studies offered the ability to study wider ranges of drug dosages compared to human studies. Thus, varying doses of CY were assessed for their effects on lymphocyte numbers, as well as function measured by in vitro proliferative responses and soluble mediator production.

\section{METHODS}

Immunization. Strain 13 inbred guinea pigs from the NIH breeding colony were made tuberculin sensitive by footpad injection of a total of $0.4 \mathrm{ml}$ of complete Freund's adjuvant (CFA) containing $2 \mathrm{mg} / \mathrm{ml}$ of Mycobacterium tuberculosis $\mathrm{H} 37 \mathrm{Ra}$ (Difco Laboratories, Detroit, Mich.).

Drug administration. Guinea pigs immunized with CFA 2-4 wk previously were treated with daily intraperitoneal injections of saline or cyclophosphamide (Cytoxan, Mead Johnson Laboratories, Evansville, Ind.) for 5 consecutive days. On day 6, blood, spleen, and lymph nodes were harvested for study.

Preparation of lymphoid cells. Peripheral blood lymphocytes (PBL) were obtained from guinea pigs bled by intracardiac puncture into syringes containing acid-citrate anticoagulant. Aliquots were taken for total leukocytes measured by a Coulter Counter (Coulter Electronics Inc., Hialeah, Fla.). Leukocyte differential counts were obtained from Wright's stained blood smears by counting 200 total cells.

The remainder of the blood was separated in a modification of the Hypaque-Ficoll method of Böyum (6). The mononuclear cells were washed once with $0.85 \%$ saline and twice with Eagle's minimal essential medium (MEM-S) (Grand Island Biological Co., Grand Island, N. Y.). These cells, containing $>95 \%$ mononuclear cells with $<5 \%$ polymorphonuclear cells, were then used for macrophage migration inhibitory factor (MIF) and lymphocyte proliferation assays. After exsanguination, axillary and popliteal lymph nodes and spleens were aseptically removed. These organs were separately sliced into small fragments, teased, and finally gently forced through 60 -mesh wire screens. The dispersed populations of cells were then layered over $\mathrm{Hy}$ paque-Ficoll gradients. The resulting mononuclear cell preparation from each organ was $>90 \%$ viable as measured by the trypan blue dye exclusion text.

Antigens and mitogens. Purified protein derivative (PPD) of $M$. tuberculosis (Connaught Medical Research Labs., Toronto, Canada) was used for lymphocyte transformation and MIF responses. Phytohemagglutinin (PHA) MR 68 (The Wellcome Research Laboratories, Beckenham, Kent, England), and concanavalin A (Con A) (Nutritional Biochemicals Corp., Cleveland, Ohio) were used in lymphocyte proliferation assays.

Lymphocyte proliferation assay. The Hypaque-Ficoll separated PBL, splenic, and lymph node lymphocytes (LNL) were suspended in MEM-S containing $10 \%$ normal guinea pig serum at a final density of $1 \times 10^{\circ}$ cells $/ \mathrm{ml}$ with various concentrations of antigen or mitogens as will be described in individual experiments. Lymphocytes were cultured as has previously been described (7). Briefly, cell cultures were prepared in microtiter plates (Cooke Laboratory Products Div., Dynatech Laboratories, Inc., Alexandria, Va.). Quadruplicate wells, each containing $2 \times 10^{5}$ cells, were prepared for each antigen or mitogen concentration to be tested. PHA- and Con A-stimulated cultures consistently showed peak proliferative responses after 3 days of culture, while PPD responses peaked at 4 days. $18 \mathrm{~h}$ before harvesting, $0.4 \mu \mathrm{Ci}$ of tritiated thymidine $(6.7 \mathrm{Ci} /$ $\mathrm{mM}$, New England Nuclear, Boston, Mass.) was added to each well. The cells were collected from the wells onto Fiberglas filters using a semiautomated microharvesting device. The filters were washed with $10 \%$ trichloroacetic acid (TCA) and 95\% ethanol, then placed in vials containing $10 \mathrm{ml}$ of scintillation fluid (Aquasol, New England Nuclear). The TCA-precipitable radioactivity was counted in a liquid scintillation counter (Beckman Instruments, Inc., Fullerton, Calif.). The arithmetic mean of the counts per minute (cpm) of quadruplicate cultures was determined and the degree of stimulation expressed as the difference in cpm per $10^{8}$ lymphocytes between stimulated and unstimulated (control) cultures $(\Delta \mathrm{cpm})$.

MIF assay. Peritoneal exudate cells (PEC) were prepared from nonimmunized guinea pigs as previously described (8). The MIF response of PPD-stimulated PBL, LNL, and splenic lymphocytes from guinea pigs immunized with CFA was assessed by mixing Hypaque-Ficoll-separated cells with PEC from syngeneic nonimmunized animals. The mixture of immune lymphocytes and nonimmune PEC was suspended in MEM-S at $6 \times 10^{7}$ cells $/ \mathrm{ml}$. These cells were drawn into $50-\mu 1$ capillary pipets (one end was sealed by flaming) and centrifuged at $130 \mathrm{~g}$ for $5 \mathrm{~min}$. The capillaries were fractured at the cell-fluid interface and fixed to well bottoms of $16-\mathrm{mm}$ tissue culture trays (Linbro Chemical Co., New Haven, Conn.) by sterile stopcock grease. Immediately, the capillaries were covered with 0.9 $\mathrm{ml}$ of media (MEM-S containing $15 \%$ normal guinea pig serum, supplemented with $0.2 \mathrm{M}$ L-glutamine, $100 \mathrm{U} / \mathrm{ml}$ penicillin, and $100 \mu \mathrm{g} / \mathrm{ml}$ streptomycin). Various concentrations of PPD were added as will be described in each experiment. After $18 \mathrm{~h}$, the trays were carefully removed from the incubator and three drops of $25 \%$ glutaraldehyde were added to each well to fix the cells before measurement of cell migration. The areas of macrophage migration were traced, 20 times enlarged, on a Nikon profile projector (Nippon Kogaku K. K., Japan) and measured by a planimeter. 
The percent migration inhibition was calculated as follows: $\%$ inhibition $=100-($ mean area with antigen $) /($ mean area without antigen $) \times 100$.

\section{RESULTS}

Effects of increasing doses of $C Y$ on peripheral leukocytes. Guinea pigs were divided into four groups each of which received either 0 (saline), 5,10 , or $20 \mathrm{mg} / \mathrm{kg}$ of CY intraperitoneally for 5 consecutive days. The 20 $\mathrm{mg} / \mathrm{kg}$ per day dose of $\mathrm{CY}$ is equivalent to approximately $200 \mathrm{mg} / \mathrm{m}^{2}$ body surface area per day. The mean ( \pm SEM) total leukocyte count measured on day 6 for groups of six animals each receiving $0,5,10$, and 20 $\mathrm{mg} / \mathrm{kg}$ of $\mathrm{CY}$ was $7,065( \pm 731), 5,073( \pm 421), 4,123$ $( \pm 1,281)$, and $1,615( \pm 149)$, respectively. The effect of increasing doses of $\mathrm{CY}$ on the absolute numbers of neutrophils and lymphocytes is shown in Fig. 1. Though there was no morbidity or mortality observed in any of the CY treatment groups during this relatively shortterm study period, it is noteworthy that lymphopenia was achieved at the expense of a disproportionately severe neutropenia particularly at the $20 \mathrm{mg} / \mathrm{kg}$ dose of CY. In experiments designed to test the effects of $\mathrm{CY}$ on cell-mediated functions in vitro, $\mathrm{PBL}$ from each $\mathrm{CY}$ treatment group were compared with PBL from saline-

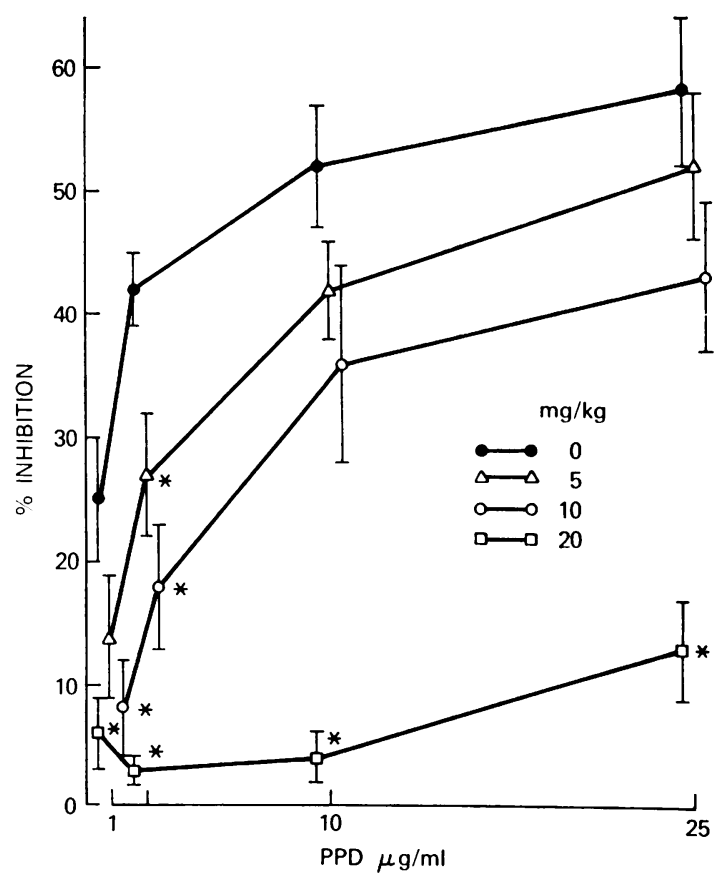

FIgURe 2 Effect of increasing doses of $\mathrm{CY}$ on MIF responses of PBL. At each concentration of PPD, MIF responses of CY-treated PBL were compared to responses of controls. Values represent the mean $( \pm S E M)$ percent migration inhibition of four separate experiments; statistically significant differences are indicated by asterisks ( $P$ $<0.05$ )

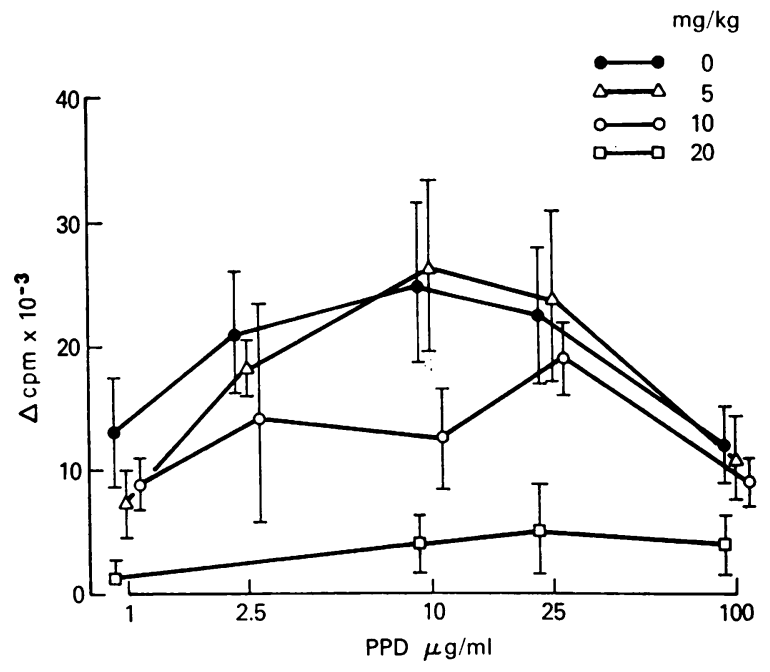

Figure 3 Effect of increasing doses of CY on PPDinduced proliferative responses of PBL. Mean ( \pm SEM) $\Delta \mathrm{cpm}$ as a function of PPD concentration is indicated for each CY treatment group from three separate experiments.

treated (control) groups for their ability to produce MIF and undergo proliferation in response to antigen and mitogens.

Effect of $C Y$ on MIF production of PBL. After 5 days of treatment, $\mathrm{PBL}$ from each $\mathrm{CY}$ treatment group $(5,10$, and $20 \mathrm{mg} / \mathrm{kg})$ were compared to equal numbers of PBL from the saline control group by mixing in a ratio of $1: 4$ with $\mathrm{PEC}$ from syngeneic, nonimmune guinea pigs. The percent of migration inhibition in response to increasing concentrations of PPD was assessed for each cell mixture, as shown in Fig. 2. There was a dose-dependent suppression of MIF responses, with differences in the low-dose CY ( 5 and $10 \mathrm{mg} / \mathrm{kg}$ ) groups being apparent only at low concentrations of PPD, while $20 \mathrm{mg} / \mathrm{kg}$ of CY suppressed MIF responses at all concentrations of PPD. The possibility that disproportionately greater rates of cell death subsequent to initial preparation of the assays could explain the difference in MIF responses between $\mathrm{CY}$ and control groups was unlikely, since the numbers and viabilities of PBL from control and CY $(20 \mathrm{mg} / \mathrm{kg})$ groups cultured separately for $24 \mathrm{~h}$ were equivalent. Thus, although CY produces a significant, dose-dependent peripheral lymphocytopenia, it also reduces the functional capacity of those lymphocytes remaining in the circulation to produce MIF, a soluble mediator of cell-mediated reactions.

Effects of $C Y$ on antigen- and mitogen-induced proliferation of $P B L$. Aliquots of Hypaque-Ficoll preparations of PBL for MIF assay were simultaneously cultured in lymphocyte transformation assays. The proliferative response $(\Delta \mathrm{cpm})$, as a function of increasing concentrations of PPD, is shown in Fig. 3 for groups 
TABLE I

Effect of $C Y$ on Mitogen Responses of PBL

\begin{tabular}{|c|c|c|c|c|c|}
\hline \multirow{3}{*}{$\begin{array}{l}\text { Dose } \\
\text { CY }\end{array}$} & \multirow{3}{*}{$\begin{array}{c}\text { Number } \\
\text { of } \\
\text { experi- } \\
\text { ments }\end{array}$} & \multicolumn{4}{|c|}{ Mean $\%( \pm$ SEM $)$ of control $\Delta \mathrm{cpm} *$} \\
\hline & & \multicolumn{2}{|c|}{ PHA, $\mu g / m l$} & \multicolumn{2}{|c|}{ Con A, $\mu g / m l$} \\
\hline & & 0.5 & 1.0 & 5 & 10 \\
\hline \multicolumn{6}{|c|}{$m g / k g$} \\
\hline 5 & 4 & $\begin{array}{c}145 \\
( \pm 18)\end{array}$ & $\begin{array}{c}117 \\
( \pm 14)\end{array}$ & $\begin{array}{c}144 \\
( \pm 23)\end{array}$ & $\begin{array}{r}137 \\
( \pm 17)\end{array}$ \\
\hline 10 & 3 & $\begin{array}{r}76 \\
( \pm 28)\end{array}$ & $\begin{array}{r}82 \\
( \pm 11)\end{array}$ & $\begin{array}{c}142 \\
( \pm 29)\end{array}$ & $\begin{array}{c}135 \\
( \pm 10)\end{array}$ \\
\hline 20 & 5 & $\begin{array}{r}25 \ddagger \\
( \pm 8)\end{array}$ & $\begin{array}{r}50 \\
( \pm 25)\end{array}$ & $\begin{array}{r}50 \\
( \pm 20)\end{array}$ & $\begin{array}{r}56 \\
( \pm 18)\end{array}$ \\
\hline
\end{tabular}

* Responses of CY-treated PBL were compared to simultaneously tested saline-treated (control) PBL.

$\ddagger$ Significantly different from control response $(P<0.001)$ by $t$ test analysis.

receiving $0,5,10$, and $20 \mathrm{mg} / \mathrm{kg}$ of $\mathrm{CY}$. Although the mean values for $\Delta \mathrm{cpm}$ at low concentrations of PPD were lower in PBL from groups treated with 5 and 10 $\mathrm{mg} / \mathrm{kg}$ of CY compared to saline-treated controls, only $20 \mathrm{mg} / \mathrm{kg}$ of CY showed a statistically significant suppression of lymphocyte proliferation as measured by incorporation of tritiated thymidine into DNA. The proliferative responses of mitogen-stimulated PBL from each treatment group were similarly compared. Because

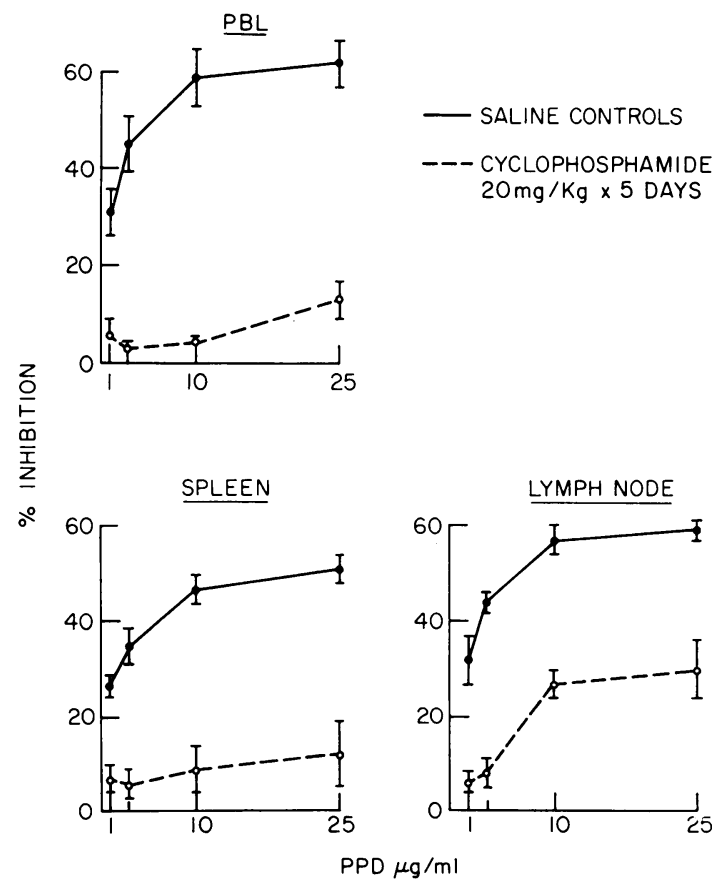

FIgURE 4 Comparison of the ability of CY to suppress MIF responses of PBL, spleen, and lymph nodes. Values represent the mean ( \pm SEM $) \%$ migration inhibition of four separate experiments.

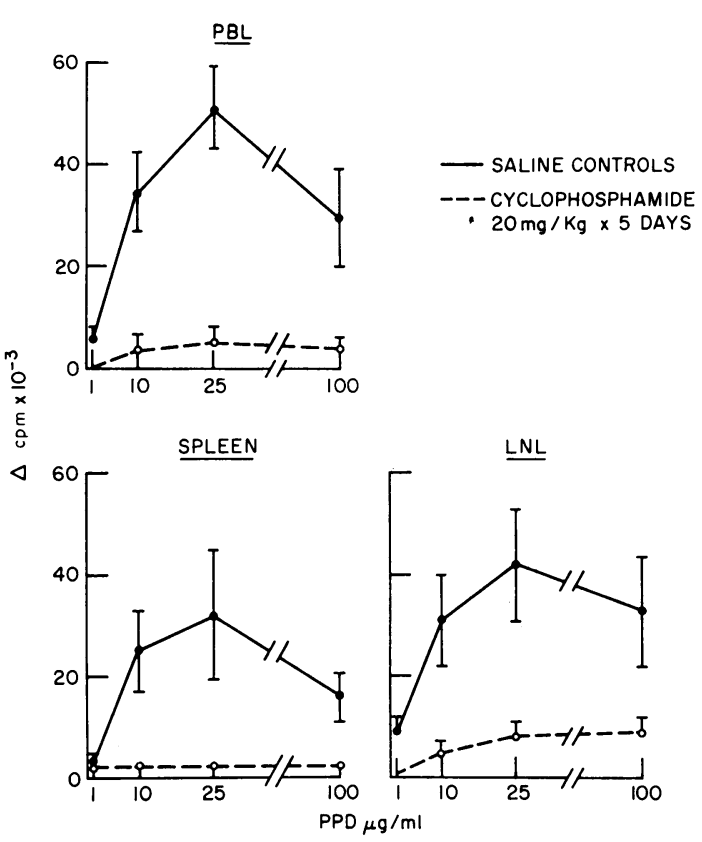

Figure 5 Comparison of the ability of CY to suppress $\mathrm{PPD}$-induced proliferative responses of $\mathrm{PBL}$, spleen, and lymph nodes. Values represent the mean ( \pm SEM) $\Delta \mathrm{cpm}$ of four separate experiments.

the absolute value of $\Delta \mathrm{cpm}$ in both treated and control PBL showed marked day-to-day variability in PHA and Con A experiments, the data is expressed as follows: pairs of treated and control animals were simultaneously studied, and the $\Delta \mathrm{cpm}$ generated by $\mathrm{PBL}$ from $\mathrm{CY}$-treated animals was expressed as a percent of the $\Delta \mathrm{cpm}$ generated by simultaneously assayed control PBL. Optimal proliferative responses for PHA and Con A were produced by 1.0 and $10 \mu \mathrm{g} / \mathrm{ml}$, respectively. As shown in Table I, CY caused a progressive reduction in both PHA and Con A responses; however, only the response of the PBL from the $20 \mathrm{mg} / \mathrm{kg} C Y$, stimulated with a suboptimal dose $(0.5 \mu \mathrm{g} / \mathrm{ml})$ of PHA, was statistically different from the response of saline-treated control PBL. Thus, the proliferative response of PBL remaining in the circulation to mitogens is relatively well-preserved, in contrast to the marked suppression of antigen-induced proliferation during $\mathrm{CY}$ treatment.

Effect of CY treatment on the cell-mediated functions of lymph nodes and spleen. To evaluate whether the suppressive effect of $\mathrm{CY}$ on lymphocyte function was peculiar to PBL or general for other lymphoid organs, the effect of high dose $(20 \mathrm{mg} / \mathrm{kg}) \mathrm{CY}$ was tested on the MIF and proliferative responses of splenic and LNL. Splenic and LNL from CY-treated immune animals were mixed in ratios of $1: 4$ and $1: 9$, respectively with PEC from nonimmune guinea pigs for MIF assay. Comparison of MIF responses from simultaneously tested PBL, spleen, and lymph nodes from $\mathrm{CY}$ vs. sa- 
line-treated animals are shown in Fig. 4. Corollary experiments were designed to compare the effect of CY on antigen-induced proliferative responses of $\mathrm{PBL}$, spleen, and lymph node. Fig. 5 shows that CY effectively suppressed the PPD-induced proliferative responses of spleen and lymph node as well as that of PBL. These experiments demonstrate that high-dose CY treatment suppresses both antigen-induced soluble mediator production and proliferative responses of sessile as well as circulating lymphocyte populations. Thus, although the major effect of low dose CY treatment has been shown to be a reduction in the numbers rather than functions of circulating lymphocytes, the ability of high-dose CY treatment to suppress lymphocyte functions as tested in vitro applies to both circulating and organ-bound lymphocyte populations.

\section{DISCUSSION}

CY has come to be recognized as a highly potent and clinically useful immunosuppressive agent. Enthusiasm for its use has come from successful results of empirical clinical trials in various diseases either caused by or associated with immunological disorders (1). CY has also been shown to produce striking amelioration of autoimmune diseases, such as allergic thyroiditis $(9,10)$, experimental allergic encephalitis (11), NZB/W disease of mice (12), and Aleutian disease of mink (13). In addition, $\mathrm{CY}$ has been shown to effectively suppress several cell-mediated immunologic reactions, such as delayed hypersensitivity skin tests (14-16), graft vs. host potential of lymphoid cells (17), and cell-mediated cytotoxicity against tumor cells (18). Though it has been well shown in experimental situations that CY treatment produces lymphopenia $(19,20)$, it remains unclear whether the therapeutic effects of CY are related primarily to depression of numbers as opposed to functions of lymphocytes. Several studies in human diseases have shown that CY causes a peripheral lymphopenia, particularly of the small lymphocyte population (21-25). Studies of the proliferative responses of antigen and mitogen-stimulated lymphocytes from CY-treated patients has led to conflicting results $(22,23,25-27)$. Whether the differences between these studies relate to variable patient populations, dose and/or duration of CY treatment, immunological techniques, or other unidentified problems remains unclear.

The present studies of the effects of CY on established cell-mediated immunity showed that low-dose CY treatment caused a moderate degree of lymphocytopenia with a relative preservation of cell-mediated functions of PBL. However, CY in high doses dramatically suppressed the numbers as well as the antigen-stimulated proliferative function of peripheral lymphocytes. The mitogen response of $\mathrm{PBL}$ was suppressed only by the highest dose of CY and only at suboptimal concentrations of PHA. This lack of parallel changes in antigen and mitogen responses reflects either a differential sensitivity of various lymphocyte functions to CY, or a selective depletion of antigen-reactive lymphocytes. The latter could represent a more rapidly proliferating subpopulation of lymphocytes which may have increased susceptibility to CY. The studies reported here, however, demonstrate that significant antiproliferative effects are seen only at doses of CY which concomitantly produced a profound neutropenia. Similar results were obtained in studies of the PHA responses of mice treated with varying doses of CY in which it was found that only significantly "toxic" doses of CY consistently suppressed lymphocyte proliferation (28).

The present studies also demonstrate that CY can effectively suppress the production of a soluble mediator or lymphokine (MIF), a lymphocyte function which is not dependent on cellular division $(29,30)$. Thus, the production of this putative mediator of cell-mediated immunological reactions can be suppressed by two distinct means: first, quantitatively by reduction of the numbers of MIF-generating lymphocytes, and second, qualitatively through interference with lymphocyte functions by high-dose CY treatment. Whether the latter effect is due to defects in antigen recognition, lymphocyte activation, MIF production, or possibly a selective depletion of MIF-producing cells remains unclear.

The effect of CY on MIF responses has previously been reported in studies in which $C Y$ was given to guinea pigs at or near the primary induction stage of cell-mediated immunity. Winkelstein reported that $\mathrm{CY}$ treatment beginning at the time of immunization with Freund's adjuvant failed to suppress subsequent MIF responses while simultaneous proliferative responses to PPD antigen were essentially ablated (31). Jokipii and Jokipii, on the other hand, showed prolonged suppression of MIF responses when CY was given 3 days before immunization (32).

Our studies have focused on the effects of CY on preexisting cell-mediated immune responses, since it was felt that such an approach would be relevant to the use of immunosuppressive agents in clinical practice, where it is usually the ongoing immunological process which is being treated. It was found that increasing doses of CY produced a progressive peripheral lymphopenia, with a progressive reduction in MIF and proliferative responses to antigen, but not mitogens, in the remaining lymphocyte population. Corresponding changes in these functions were also seen in other lymphocyte populations, such as the spleen and lymph node.

The relationship of the observations in the animal studies reported here to clinical situations will depend on further elucidation of the relationships of 
changes in lymphocyte numbers and functions to therapeutic responses in various disease states. Recent studies have shown that the activity of certain diseases improved by CY is associated with a reduction of lymphocyte numbers, but not with a detectable depression of mitogen-induced lymphocyte proliferation $(22,23)$. These studies, in conjunction with the findings of the present report, caution that the adequacy of immunosuppressive therapy with CY may not be safely monitored by tests of in vitro mitogen responses of lymphocytes, since doses of CY which suppress these lymphocyte functions may be associated with potential compromise of host defense mechanisms by increasing the risk of development of significant neutropenia.

\section{REFERENCES}

1. Gershwin, M. E., E. J. Goetzel, and A. D. Steinberg. 1974. Cyclophosphamide: use in practice. Ann. Intern. Med. 80: 531-540.

2. Skinner, M. D., and R. S. Schwartz. 1972. Immunosuppressive therapy. N. Engl. J. Med. 287: 221-227, and 281-286.

3. Hersh, E. M. 1973. Modification of host defense mechanisms. In Cancer Medicine. J. F. Holland and E. Frei, III, editors. Lea \& Fabiger, Philadelphia. 681-699.

4. Hurd, E. R. 1973. Immunosuppressive and antiinflammatory properties of cyclophosphamide, azathioprine and methotrexate. Arthritis Rheum. 16: 84-88.

5. David, J. R., and R. R. David. 1972. Cellular hypersensitivity and immunity. Prog. Allergy. 16: 300-449.

6. Böyum, A. 1968. Isolation of mononuclear cells and granulocytes from human blood. Scand. J. Clin. Lab. Invest. 21 (Suppl. 97) : 77-89.

7. Balow, J. E., D. L. Hurley, and A. S. Fauci. 1975. Immunosuppressive effects of glucocorticosteroids: differential effects of acute versus chronic administration on cell mediated immunity. J. Immunol. 114: 1072-1076.

8. Balow, J. E., and A. S. Rosenthal. 1973. Glucocorticoid suppression of macrophage migration inhibitory factor. J. Exp. Med. 137: 1031-1041.

9. Salvin, S. B., and H-L. Liauw. 1967. Immunologic unresponsiveness to allergic thyroiditis in guinea pigs. $J$. Immunol. 98 : 432-441.

10. Nakamura, R. M., and W. O. Weigle. 1971. Suppression of thyroid lesions in rabbits by treatment with cyclophosphamide after the induction of thyroiditis. Clin. Exp. Immunol. 7 : 541-550.

11. Paterson, P. Y. 1971. Cyclophosphamide treatment of experimental allergic encephalomyelitis in Lewis rats. J. Immunol. 106 : 1473-1479.

12. Gelfand, M. C., and A. D. Steinberg. 1972. Therapeutic studies in NZB/W mice. II. Relative efficacy of azathioprine, cyclophosphamide, and methylprednisolone. Arthritis Rheum. 15 : 247-252.

13. Cheema, A., J. B. Henson, and J. R. Gorham. 1972. Aleutian disease of mink: prevention of lesions by immunosuppression. Am. J. Pathol. 66: 534-551+4 plates.
14. Arinoviche, R., and G. Loewi. 1970. Comparison of the effects of two cytotoxic drugs and of antilymphocyte serum. Ann. Rheum. Dis. 29: 32-39.

15. Salvin, S. B. 1965. Contact hypersensitivity, circulating antibody, and immunologic unresponsiveness. Fed. Proc. 24: $40-44$.

16. Winkelstein, A. 1973. Mechanisms of immunosuppression: effects of cyclophosphamide on cellular immunity. Blood. 41: 273-284.

17. Fink, M. P., and C. L. Cloud. 1974. Graft-versus-host disease in rats after donor treatment with cyclophosphamide and spleen cells of host origin. Transplantation (Baltimore). 17 : 508-512.

18. Harrington, J. T., and J. T. Fletcher. 1974. Immunosuppressive effects of cyclophosphamide on bone marrow and thymus derived lymphocyte functions in the mouse. Clin. Res. 22: 419A. (Abstr.)

19. Turk, J. L., and L. W. Poulter. 1972. Selective depletion of lymphoid tissue by cyclophosphamide. Clin. Exp. Immunol. 10 : 285-296.

20. Johansen, K. S., T. S. Johansen, and D. W. Talmage. 1974. T cell rosette formation in primates, pigs, and guinea pigs. J. Allergy Clin. Immunol. 54: 86-93.

21. Clements, P. J., D. T. Y. Yu, J. Levy, H. E. Paulus, and E. V. Barnett. 1974. Effects of cyclophosphamide on B- and T-lymphocytes in rheumatoid arthritis. Arthritis Rheum. 17 : 347-353.

22. Fauci, A. S., D. C. Dale, and S. M. Wolff. 1974. Cyclophosphamide and lymphocyte subpopulations in Wegener's granulomatosis. Arthritis Rheum. 17: 355-361.

23. Horwitz, D. A. 1974. Selective depletion of Ig-bearing lymphocytes by cyclophosphamide in rheumatoid arthritis and systemic lupus erythematosis. Arthritis Rheum. 17 : 363-374.

24. Hurd, E. R., and M. Ziff. 1974. Parameters of improvement in patients with rheumatoid arthritis treated with cyclophosphamide. Arthritis Rheum. 17: 72-78.

25. Alepa, F. P., N. J. Zvaifler, and A. J. Sliwinski. 1970. Immunologic effects of cyclophosphamide treatment in rheumatoid arthritis. Arthritis Rheum. 13: 754-760.

26. Curtis, J. E., J. T. Sharp, M. D. Lidsky, and E. M. Hersh. 1973. Immune response of patients with rheumatoid arthritis during cyclophosphamide treatment. Arthritis Rheum. 16: 34-42.

27. Winkelstein, A., J. M. Mikulla, H. R. Nankin, B. H. Pollock, and B. L. Stolzer. 1972. Mechanisms of immunosuppression: effects of cyclophosphamide on lymphocytes. J. Lab. Clin. Med. 80: 506-513.

28. Scheiffarth, F., D. Leykam, H. Warnatz, and H. W. Baenkler. 1973. Effect of cytostatic drugs on blast cell transformation of lymph node and spleen cells. Res. Exp. Med. 160: 196-205.

29. Bloom, B. R., J. Gaffney, and L. Jimenez. 1972. Dissociation of MIF production and cell proliferation. $J$. Immunol. 109: 1395-1398.

30. Rocklin, R. E. 1973. Production of migration inhibitory factor by non-dividing lymphocytes. J. Immunol. 110: 674-678.

31. Winkelstein, A. 1973. Differential effects of immunosuppressants on lymphocyte function. J. Clin. Invest. 52: 2293-2299.

32. Jokipii, A. M. M., and L. Jokipii. 1973. Suppression of cell-mediated immunity by cyclophosphamide: its independence of concomitant B cell response. Cell. Immunol. 9: $477-481$. 